\title{
REVISTA IBEROAMERICANA DE
}

Consejo General

$\frac{\text { de la Psicología }}{\text { ESPAÑA }}$

PSICOLOGÍA Y SALUD

Revista Oficial de la Federación Iberoamericana de Asociaciones de Psicología (FIAP)

[Official Journal of the Latin-American Federation of Psychological Associations]

\section{Reading span test in subjects with speech, language and communication needs (SLCN)}

\author{
Pilar Vieiro-Iglesias* y Eva Quireza-Fornos \\ Universidad A Coruña
}

- Recibido: 06 - 12 - 2020 . Aceptado: 14 - 12 - 2020 . Avance online: 28 - 12 - 2020

ABSTRACT. Working Memory (WM) is considered one of the basic components of cognition, and the measurement of WM span is very relevant to the study of individual differences in complex cognitive tasks. The aim of the present study is the adaptation of Daneman and Carpenter's Reading Span Test for use in subjects with speech, language and communication needs users of alternative o augmentative communication systems. We elaborated and administrated the new working memory test (RST-P), and finally, we analysed the relationships between the new Reading Span Test for subject with speech, language, and communication needs and digit span test. Results showed that RST-P is appropriately discriminative to measure WM span and predicts individual differences.

KEYWORDS: Working memory, Reading comprehension, Reading span test, Alternative communication systems, Communication needs.

\section{Prueba de lectura en sujetos con necesidades de habla, idioma y comunicación (SLCN)}

RESUMEN. La memoria de trabajo (MT) se considera uno de los componentes básicos de la cognición, y la medición de la amplitud de la MT es muy relevante para el estudio de las diferencias individuales en tareas cognitivas complejas. El objetivo del presente estudio es la adaptación de la Prueba de Amplitud de Lectura de Daneman y Carpenter para su uso en sujetos con necesidades de habla, lenguaje y comunicación, usuarios de sistemas de comunicación alternativos o aumentativos. Elaboramos y administramos la nueva prueba de memoria de trabajo (RST-P), y finalmente, analizamos las relaciones entre la nueva Prueba de lectura para SLCN y la prueba de memoria de dígitos. Los resultados mostraron que RST-P es apropiadamente discriminatorio para medir el alcance de MT y predice diferencias individuales.

PALABRAS CLAVE: Memoria operativa, Comprensión lectora, Reading span test, Sistemas alternativos de comunicación, Necesidades comunicativas.

The concept of working memory in its origins was included within the cognitive psychology of learning and memory. Baddley and Hitch (1974) established a specific definition and structure for working with working memory, also called working memory or short-term memory. Considered as the ability to store and manipulate information for short periods of time, the information with which one works remains active while attention

*Correspondencia: Pilar Vieiro Iglesias.

Universidad A Coruña (España)

Dirección: 15071. Facultad Ciencias Educación. A Coruña.

España.

E-mail: pilar.vieiro@udc.es

(C) 2021 Sociedad Universitaria de Investigación en Psicologíay Salud. Publicado por Consejo General de Colegios Oficiales de Psicólogos, España. Este es un artículo Open Access
bajo la CC BY-NC-ND licencia (http://creativecommons.org/licencias/by-nc-nd/4.0/)

Citar como/Cite as: Vieiro-Iglesias, P. y Quireza-Fornos, E. (2021). Reading span test in subjects with speech, language and communication needs (SLCN). Revisto Iberoamericana de Psicología y Salud, 12(1), 34-43. Doi: https://doi.org/10.23923/i rips.2021.01.043 is given to it, but it will decline the moment attention is focused on different information. It is a mental workspace that can be used to support cognitive skills that require significant information storage. It develops mainly between the ages of five and eleven, and differs from short-term memory mainly in that it is not a single system, it plays a priority role in learning, reasoning, and understanding.

Working memory is mainly made up of a series of elements: 1) Central executive which function is to control and regulate the entire operating memory system. Initially, this function involved only the coordination of subsidiary systems, the focus of attention, attention change, 
and the activation of representations in longterm memory (Baddeley and Hitch, 1974). Subsequently, functions such as active inhibition or suppression of arrogant responses or irrelevant information, control and updating of the content of working memory were added to it (Baddeley, 2003; Gathercole \& Baddeley, 2014; Logie, 2016; Morrison \& Chein, 2011); 2) Phonological loop which function is the active maintenance of verbal information through review mechanisms. It is made up of two subcomponents: a passive phonological store whose function is to represent information in a phonological propositional format with a limited duration and capacity, and an active phonological review subsystem whose function is to refresh the representations of the phonological store so that they do not decay with the time (Baddeley \& Hitch, 2019; Gathercole \& Baddeley, 2014; Paulesu et al., 2017); 3)

Visuo-spatial scratchpad, like the previous one, its function is the active maintenance of information, but in this case with a visual-spatial image format. It would also be made up of two subcomponents: a passive visual warehouse with the function of retaining visual information that has not yet been encoded, and an active visual processing subsystem whose function is to encode visual information, transforming and integrating it (Logie \& Morris, 2014; Nadler \& Archibald, 2014; Vugs, Cuperus, Hendriks, \& Verhoeven, 2013); and 4) Episodic buffer of working memory is a limited capacity storage system responsible for integrating information from several sources to create a unified memory, sometimes referred to as a single 'episode'. The episodic buffer does this by "binding" information from the various systems of working memory (e.g. phonological loop, visuospatial sketch pad) and relevant activated long-term semantic and linguistic knowledge, into a coherent whole. The information stored in it would be related to long-term memory and semantic meanings (Baddeley, 2000, 2017).

Working memory is widely acknowledged as having limited capacity. The capacity limit associated with short-term memory was the "magical number seven" suggested by Miller in 1956. He claimed that the informationprocessing capacity of young adults is around seven elements, which he called "chunks".
Working memory capacity can be tested by a variety of tasks. A commonly used measure is a dual-task paradigm, combining a memory span measure with a concurrent processing task, sometimes referred to as "complex span" (MelbyLervåg \& Hulme, 2013; Farmer, Fine, Misyak \& Christiansen, 2017; Riascos, Brugger, da Luz Fontes \& Barone, 2019). Daneman and Carpenter invented the first version of this kind of task, the "reading span", in 1980. The test process consists of presenting the subject with a series of unrelated sentences from which the last word of each one must be memorized. You will start with the reading aloud and at the necessary pace of all the phrases that make up the task and then, respecting the order of appearance, you must repeat the memorized words orally. The test is made up of several phases that will progressively increase its difficulty, increasing the number of sentences that compose them as well as the difficulty in semantic structures. The sentences will be presented alone on the paper and exclusively during the reading to avoid facilitating the memorization of the words.

The structure of the test consists of five phases consisting of two, three, four, five and six sentences respectively and three series per level, that is, a total of sixty sentences in total. The subject advances in phase at the moment in which he is able to complete at least two of the three series correctly.

In this context, several studies showed that subjects with current language impairment showed impairment in all verbal memory measures compared with subjects who had never had language impairment. The severity of verbal memory impairment correlated with the degree of language impairment, so in language impairment there is domain specificity of memory impairment affecting verbal processing (Archibald \& HarderGriebeling, 2016; Baird, Dworzynski, Slonims, \& Simonoff, 2010; Chonan \& Sawa, 2017). Over the past decade, evidence for the linkage between the language and memory problems of children with SLI has grown. Children with specific language impairment (SLI) show memory deficits in both phonological short-term memory (Archibald \& Gathercole, 2006; Hill, van Santen, Gorman, Langhorst, \& Fombonne, 2015) and working memory (Archibald, 2013; K lem et al., 2015). 
Verbal WM research on children with SLI has primarily been carried out with respect to two dominant models: that of Baddeley and Hitch (Baddeley, 2003; Baddeley \& Hitch, 1974) and that of Daneman and Carpenter (1980). The current study is based on the Baddeley and Hitch mode Verbal WM research on children with SLI has primarily been carried out with respect to two dominant models: that of Baddeley and Hitch (Baddeley, 2003; Baddeley \& Hitch, 1974) and that of Daneman and Carpenter (1980). The current study is based on the last model. In the original RST (Daneman \& Carpenter, 1980), participants were instructed to read series of sentences aloud, while remembering the final word of each sentence in a particular series. The sentences were presented on cards, one sentence on each card, and at the end of a series a blank card appeared, which was the participant's cue for recall. It was the participant's task to recall all sentence-final words in the right order. The number of sentences in a series was gradually increased. The reading span was the maxi-mum number of final words that were correctly recalled. The RST is a so-called "complex" verbal working-memory test since it taps both the storage and processing elements of working memory, whereas "simple" verbal working-memory tests only tap the storage element. In addition, Daneman and Carpenter (1980) developed a listening version of the RST. The listening span also requires the retention of sentence-final words, but the participant listened to, rather than read, lists of sentences. In the last decades, several variants of the RST have been developed based on the original test.

For it, we design a test which allows evaluate the amplitude of verbal working memory in this type of subjects and that these are different from the classic tests directed at the normative population as can be "Wide Range Assessment of Memory and Learning" or "Digit span test". We show an adaptation of the Reading Span Tets with pictograms destined to specific language impairment subjects.

In this context, we pretend to offer a test that $t$ allows a $n$ appropriate estimation $n$ of the opera tio na I me mory invo lved in read ing co $\mathrm{mp}$ re he nsio $\mathrm{n}$ in spec ific la ngua ge imp a irment subjec ts.

\section{METHOD}

\section{-PARTICIPANTS}

Six subjects with speech, language, and communication needs participated in our study using simple random sampling. All were augmentative and alternative communication users. They were readers and did not present comprehension problems in simple sentences.

\section{-SUBJECT 1}

It is a case of hearing impairment associated with an intellectual disability. Forty years old user. He communicates through sign language. The main difficulty was presented when explaining the methodology of the test, however, it was one of the best scores obtained in the whole test.

\section{-SUBJECT 2}

Man of fifty- two years. Case of Down syndrome associated with an intellectual disability. In this case, the scant attention paid to the test, made it difficult to obtain concrete results, however, as the test progressed and the methodology was automated, the work improved considerably.

\section{-SUBJECT 3}

Woman of fifty years, with hearing and intellectual disability. She communicates through sign language, uses the pictograms as an augmentative system of communication. He began the task actively, but he lost motivation as the test progressed, as well as loss of interest in noticing that the test presented difficulties that he could not overcome.

\section{-SUBJECT 4}

Male user of sixteen years of age. He suffers from polymalformative syndrome and maturational delay. His level of oral communication is limited, so his main means is communication through pictograms. He presents a constant attention in the activity, except for moments in which he became distracted at 
the moment in which pictograms of his liking appeared. The results obtained in this case were clear and precise.

\section{-SUBJECT 5}

Male teenager of fifteen years of age. User with Static lesion in the Central Nervous System of pre- or postnatal etiology and associated with an intellectual disability. He has an average oral communication, but sometimes understanding is difficult, so he uses the pictograms as the main way to communicate with others. During the test a lively and hard-working attitude was shown at all times.

\section{-SUBJECT 6}

Usersuffering from partial trisomy $10 q$ Terminal and intellectual disability. Male subject of 16 years of age. His capacity for oral communication is almost non-existent, so the pictograms are the basis of this user's communication with others. During the test, he was nervous and reluctant to perform the exercise, so it was necessary to collaborate on behalf of the center's speech therapist.

\section{- MATERIALS}

The approach of this research is designed to be carried out on users of Alternative Communication Systems, specifically using pictograms as the main means. In the center in which the research was carried out, a communication methodology based on pictograms, called the PECS methodology, is applied. There are cases in which this methodology is used as an exclusive method of communication, while in other cases, it is combined with the use of sign language or oral communication whenever possible, all associated with a diverse intellectual disability.

At the time of making the selection of the sample, and taking into account the personal information of each user provided by the speech therapist of the center, those users who do not have oral communication capacity or through sign language have been discarded. In this way the realization of the test will be carried out in a more fluid way and without the need of resorting to additional aid.
The test was created based on a series of phrases elaborated beforehand, and represented by SPC-type pictograms.

The first step of the investigation was to check the level of transparency of the pictograms that will be used to pass the test correctly, facilitating the work of both users and professionals who will participate in it, and allowing results to be obtained. more possible objectives.

This task was carried out directly with the users. Individually, he was presented with a series of printed images. Then, they were named such nouns, waiting for the subsequent identification and signaling by the user. A follow- up sheet was kept in which the results of each evaluation were recorded, writing those pictograms that were not identified, so that they were replaced by others.

In each of the cases, there was at least one pictogram that was not recognized by the user, but there is one in particular that is common to all users, the one that represents the verb "SEE", in the pictogram presented, the image does not it was clear, since it was an image in which a subject performed the action through a characteristic gesture, while the one used finally represented a pair of eyes, which for users represents a greater amount of information and form more concise.

To solve the problem, the speech therapist who usually works with them, provided the pictogram that she uses in her daily work despite belonging to another category (ARASAAC Aragonese Center of Augmentative and Alternative Communication), and that represented the image of a pair of eyes, which provided the complete meaning clearly and concisely.

Once purchased that all the symbols used are transparent for the subjects to whom the test was applied, the work was dedicated to the sentences that make up the test itself. The nontransparent pictogram was replaced by the one provided by the speech therapist at the center. Afterwards, the content of each of the sentences was analyzed, studying the coherence of the information that it contributes and valuing the ease of understanding that each of them would suppose at the moment of applying them. The unnecessary pictograms were eliminated and replaced by different ones to avoid introducing non-transparent terms. 
From here and all the transparent pictograms for the users were selected and, therefore, once the sentences with a joint and logical meaning for them were made, they were printed for their later application.

Once purchased that all the symbols used are transparent for the subjects to whom the test was applied, the work was dedicated to the sentences that make up the test itself. The nontransparent pictogram was replaced by the one provided by the speech therapist at the center. Afterwards, the content of each of the sentences was analyzed, studying the coherence of the information that it contributes and valuing the ease of understanding that each of them would suppose at the moment of applying them. The unnecessary pictograms were eliminated and replaced by different ones to avoid introducing non-transparent terms.

To evaluate the transparency of the symbols participated speech therapists from the school attended. Cohen's kappa was used to measure agreement in the evaluations of the two evaluators. The reason for using Cohen's kappa was that the raters were specifically selected and fixed. Two trials per rater were used. And the kappa value was of .80 .

From here and all the transparent pictograms for the users were selected and, therefore, once the sentences with a joint and logical meaning for them were made, they were printed for their later application.

The different sentences were formed by content words and function words. The content words were represented by pictograms (these were nouns and verbs), the words function (fundamentally articles and article-preposition contractions were represented by an empty space of content and whose objective was simply to facilitate the reading of the phrase). Regarding the length of the sentences, these were simple sentences that did not exceed three words content. All of them had the same structure: subject + verb + direct object

The length of the last word of the sentence was also controlled, all of them were bisyllables. As shown by previous studies in reading with the population under study (Dahlgren-Sandberg, Smith, \& Larsson, 2010; Smith \& Connolly, 2008) these mostly use the route phonological so the length of the word could be a strange variable that interferes with the results of the study.

Once the material used for the test has been drawn up, and the number of users with whom it will be worked has been established, we proceeded individually and with the collaboration of the speech therapist present at all times, to the execution of the final test.

In this adaptation, both the length and the structure of the sentence are respected, except that the semantic content would be adapted so that the sentences had a simpler sense of understanding for the subjects who would carry it out.

Among the adaptations that were carried out, are:

- The change of support used: The cards are set aside to use the computer screen. Once a sentence is read, it will be moved to the next page. At the moment in which the subject must repeat the words, a question mark will appear that the subject will interpret so that the exercise will begin.

- Elimination of one of the conditions of the test, which consisted in reproducing the memorized words in the same order in which they were read.

- An additional bonus is added associated with the resolution of a phase with a result better than the average established to surpass this phase with a better result than the average established to overcome this phase.

If both original and adapted scoring criteria are analyzed, after several studies, it has been concluded that those originally presented, evaluate too strictly while those resulting from adaptation are too compromising. The decision was made to elaborate a third evaluation criterion combining the two previous ones so that a balanced and objective evaluation is achieved.

To begin with, the sample file was presented, explaining clearly the procedure to be followed. The next step was to apply the phase formed by three elements in each series. In the event that the phase is overcome (remembering at least all the elements of two of the three series), the next phase will be applied, which in turn will be the last one to be executed. In order to overcome this phase, 
the same evaluation criteria will be applied as in the previous phase.

Say that before the application of the same was given to each of the subjects as following:

Next we are going to present you a series of images of successive way that form a phrase, later you will have to remember the last word of each phrase.

We presented three attempts as a test and, afterwards and once we made sure that each subject had understood the dynamics of the test, we proceeded to the final application of it.

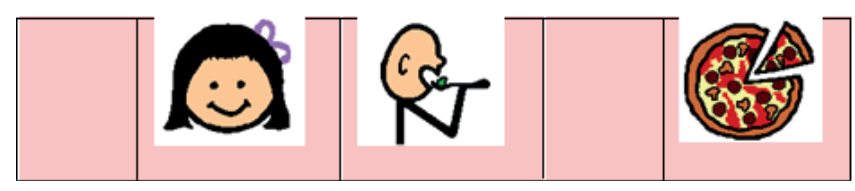

"This girl eats a pizza"

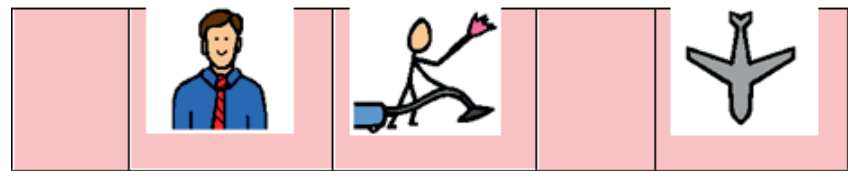

"The man cleans the plane"

? (recall phase)

"The witch looks at the monkey"

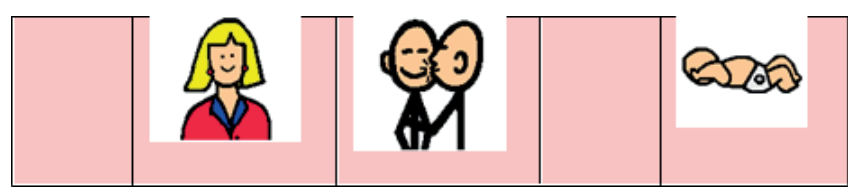

"Mom kisses the baby"

? (recall phase)

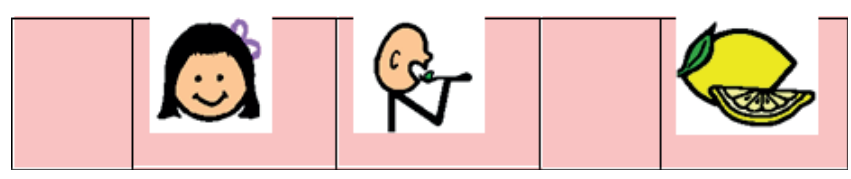

"The girl eats a lemon"

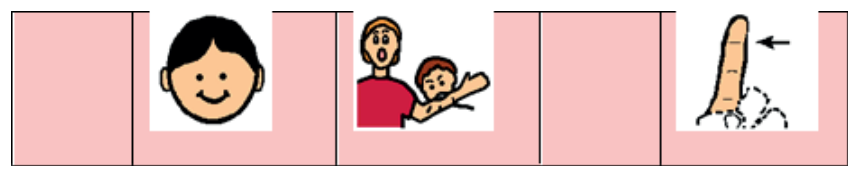

"The boy bites his finger"

? (recall phase)
And so consecutively, we are expanding the number of sentences (three of three, four of three, etc.).

The procedure used during the application of the test was as follows:

1.Reading the sentences several times. The first of them, read with the help of the professional, and the following ones in a joint way with the users, until they are able to read it autonomously and with the minimum possible help.

2. The final pictograms of the three sentences presented on each page will be covered.

3. The user will read the sentence autonomously and must remember the missing pictogram and reproduce it orally, or through the sign in the case of users with hearing impairment.

\section{-SCORE}

A series of scoring criteria have been applied to all users and in each of the phases:

- Two will be awarded for each series that is performed correctly, that is, to remember all the elements in the correct order.

- It will score with one point if all the elements are remembered even if the order is not correct.

- Results obtained with the above criteria will be multiplied by the level corresponding to said series.

- A bonus of 0.5 points will be granted in the case that all the series of the corresponding phase are completed.

\section{RESULTS}

Results obtained vary according to each case, since a series of adaptations were necessary at the moment of the execution of the test, since each of the subjects presents specific needs and supports in order to understand and analyze their results in a objective There are cases in which only phase three was exceeded, while in others stage four was also exceeded. 
Tabla 1

Results in Reading Span Test adaptation.

\begin{tabular}{|c|c|c|c|c|c|}
\hline SUBJECT & $\begin{array}{c}\text { HIGHEST PHASE } \\
\text { REA CHED }\end{array}$ & RESULTS PHASE 2 & RESULTS PHASE 3 & $\begin{array}{c}\text { RESULTS PHAASE } \\
4\end{array}$ & TOTA L SCORE \\
\hline 1 & 4 & 12,5 & 18,5 & 12 & 43 \\
\hline 2 & 3 & 12,5 & 12 & --- & 24,5 \\
\hline 3 & 3 & 12,5 & 18,5 & --- & 47 \\
\hline 4 & 4 & 12,5 & 18,5 & 16 & 47 \\
\hline 5 & 4 & 12,5 & 18,5 & 16 & 24,5 \\
\hline 6 & 3 & 12,5 & 12 & --- & 47 \\
\hline
\end{tabular}

Table 1 presents the results individually in Reading Span Test adaptation: the last phase exceeded by each one, as well as the data corresponding to each of the phases that have been surpassed by the users and the total of the sum of them.

Results show that all subjects pass phase 3 and three of them reach stage 4, this means that three of them are able to keep three active elements active when they must be remembered in context, the other three are capable of keep assets up to 4 items.

With analyzing the results of phase 3 , in which the differences between the subjects begin to appear, a preliminary idea of the results that would be obtained later can be obtained; those who obtain higher scores in that phase, would be those who passed the next phase without complications.
If the individual results are compared with the overall average obtained, it is observed that half of the evaluated ones (3) surpasses the average values, while the other half does not reach that value. The comparison between the individual results with respect to the mean, reveals an important difference between the average and the rest of the scores, whether they are scores above or below the average. The difference between them is considerable both above and below.

The evaluation of the visual working memory, through the Visual Span Test, reveals a span or average memory amplitude of 4 points, both in the direct mode (see Table 2) and in reverse (see Table 3). These scores correspond to a 50th percentile in both cases.

Tabla 2

Sequences and results of the direct modal visual span test.

\begin{tabular}{|c|c|c|c|c|}
\hline Levels & Test 1 & R/I & Test 2 & R/I \\
\hline 1 & $3-10$ & $R$ & $7-4$ & $R$ \\
\hline 2 & $1-9-3$ & $R$ & $8-2-7$ & $R$ \\
\hline 3 & $4-9-1-6$ & $R$ & $1-0-6-2-7$ & $R$ \\
\hline 4 & $4-1-9-3-8-10$ & $R$ & $5-7-9-8-2$ & $\mathrm{R}$ \\
\hline
\end{tabular}

Note. R: right; I: incorrect. 
Tabla 3

Reverse mode visual span test sequences and results.

\begin{tabular}{|c|c|c|c|c|}
\hline Levels & Test 1 & R/l & Test 2 & R/l \\
\hline 1 & $7-4$ & $R$ & $3-10$ & $R$ \\
\hline 2 & $8-2-7$ & $R$ & $1-9-3$ & $R$ \\
\hline 3 & $1-0-6-2-7$ & $R$ & $4-9-1-6$ & $R$ \\
\hline 4 & $5-7-9-8-2$ & $R$ & $6-5-1-4-8$ & $\mathrm{I}$ \\
\hline 5 & $9-2-6-7-3-5$ & $\mathrm{I}$ & $4-1-9-3-8-10$ & $\mathrm{I}$ \\
\hline Note. R: right; I: incorrect.
\end{tabular}

To analyze validity, we applied the Pearson correlation between the measurements in the adaptation of the Reading Span Test and the digit test of the WISC. A relationship was found between the digit test and the adaptation of the reading test $(r=-.44)$

\section{DISCUSSION}

Throughout our theoretical framework we have seen that the operational memory is considered as the basic substrate of cognition. In the theoretical models reviewed, the working memory is described as a mechanism of limited capacity, so the differences

of amplitude between the subjects would be at the base of the observed differential performance in complex cognitive tasks such as reading comprehension and reasoning. From there, the importance of achieving tasks designed to measure the breadth of working memory in a precise and effective manner, taking into account the activities of which it intends to be predictive, the age at which they are intended and the theoretical starting model.

Results of the study presented indicate that, indeed, the Reading Amplitude Test can be considered an appropriate measure of the operational memory involved in understanding. In this sense, and as we expected, it can be a predictive test of the extent of operational memory.
After the analysis of the test, and its subsequent application, it has been concluded that this test would be applicable to users of alternative or augmentative communication systems. However, a series of adaptations of said test will be necessary to the characteristics of the group to which this test will be applied, following recommendations of the person who knows the individual development of each of the members, as well as their personal needs (Holmes, Butterfield, \& Cormack, 2015).

In any case, we believe that together the test we offer is a good adaptation of the Reading Span Test for users of augmentative and alternative communication systems since we have tried to adjust as completely as possible the nature of the original test, as well as the adaptations made of it in the Spanish language (Elosúa et al., 1996).

It is a flexible test that allows almost any type of adaptation to access to any type of user of alternative communication systems. It is a simple test that assesses a fundamental element in cognitive development (Alloway, 2007; Alloway, Gathercole, \& Pickering, 2006; Archibald, 2013; Archibald \& HarderGriebeling, 2016).

Therefore, we hope that the data obtained from this pilot study will mark a beginning to future research that we will later expose in the open research lines. And that, in short, it constitutes a useful instrument for interested professionals and researchers to use it as an 
instrument of easy application with SAAC user subjects.

Working memory in SAAC users should be a fundamental part of the treatment, since it would greatly facilitate the knowledge of the development of each one, allowing the work done to be modified and adapted in a correct way, achieving the best possible results and a correct intellectual evolution. This research allowed us to discover the memory capacity of these users, causing surprise when comparing the results of the memory test compared to the cognitive capacity that these users present in other aspects of cognitive development.

We can extract important contributions from this research. It is important to value the memory in users of alternative systems as well as to evaluate other groups of students, taking into account the environment, the needs of the users, as well as the methodology they normally use in this type of work.

- Conflict of interest.

The authors declare no conflict of interest.

\section{REFERENCIAS}

Alloway, T. P. (2007) Automated Working Memory Assessment (AWMA). London, UK: Harcourt Assessment. $\quad$ https://doi.org/10.1016/i. jecp.2006.07.002

Alloway, T. P., Gathercole, S. E., Pickering, S. J. (2006) Verbal and visuospatial short- term and working memory in children: Are they separable? Child Development 77(6), 1698 $1716 . \quad$ https://doi.org/10.1111/i.14678624.2006.00968.x

Archibald, L. M. D. (2013). The language, working memory, and other cognitive demands of verbal tasks. Topics in Language Disorders 33(3), 190-207. https://doi. org/10.1097/TLD.0b013e31829dd8a

Archibald, L. M. D., \& Harder-Griebeling, K. (2016) Rethinking the connection between working memory and language impairment. International Journal of Language and Communication Disorders, $51(3), 252$ 264.https://doi.org/10.1111/14606984.12202
Baddeley, A. (2000). The episodic buffer: A new component of working memory? Trends in Cognitive Sciences, 4(11), 417-423. https:// doi.org/10.1016/s1364-6613(00)015382

Baddeley, A. (2003). Working memory: Looking back and looking forward. Nature Reviews Neuroscience, 4(10), 829-839. https://doi. org/10.1016/50021-9924(03)00019-4

Baddeley, A. D. (2017). Modularity, working memory and language acquisition. Second Language Research, 33(3), 299-31 1. https:// doi.org/10.1177/0267658317709852

Baddeley, A. D., \& Hitch, G. (1974). Working memory. Psychology of Learning and Motivation, 8, 47-89. https://doi. org/10.1016/S0079-7421(08)60452-1

Baddeley, A. D., \& Hitch, G. J. (2019). The phonological loop as a buffer store: An update. Cortex, 112, 91-106. https://doi. org/10.1016/i.cortex.2018.05.015

Baird, G., Dworzynski, K., Slonims, V., \& Simonoff, E. (2010). Memory impairment in children with language impairment. Developmental Medicine and Child Neurology 52(6), 535540. https://doi.org/10.1111/i.14698749.2009.03494.x

Chonan, H., \& Sawa, T. (2017). Factors related to reading span test results for hearingimpaired students. Journal of Special Education Research, 5(2), 55-63. https:// doi.org/10.6033/specialeducation.5.55

Dahlgren Sandberg, A., Smith, M., \& Larsson, M. (2010). An analysis of reading and spelling abilities of children using AAC: Understanding a continuum of competence. Augmentative and Alternative Communication, 26(3), 191 -202. https://doi.org/10.3109/074346 18.2010 .505607

Daneman, M., \& Carpenter, P. A. (1980). Individual differences in working memory and reading. Journal of Memory and Language, 19(4), 450. https://doi.org/10.1016/ S0022-5371(80)90312-6

Elosúa, M. R., Gutiérrez, F., Madruga, J. A. G., Luque, J. L., \& Gárate, M. (1996). Adaptación española del «Reading Span Test» de Daneman y Carpenter [Spanish 
adaptation of the "Reading Span Test» of Daneman and Carpenter]. Psicothema, 8(2), 383-395. Retrieved from http://www. psicothema.com/psicothema.asp?id $=37$

Farmer, T. A., Fine, A. B., Misyak, J. B., \& Christiansen, M. H. (2017). Reading span task performance, linguistic experience, and the processing of unexpected syntactic events. Quarterly Journal of Experimental Psychology, 70(3), 413-433. https://doi.org/10.1080/1 7470218.2015 .1131310

Gathercole, S. E., \& Baddeley, A. D. (2014). Working memory and language. Psychology Press.

Hill, A. P., Van Santen, J., Gorman, K., Langhorst, B. H., \& Fombonne, E. (2015). Memory in language-impaired children with and without autism. Journal of Neurodevelopmental Disorders, 7(1), 19. https://doi.org/10.1186/ s1 1689-015-9111-z

Holmes, J., Butterfield, S., \& Cormack, F. (2015). Improving working memory in children with low language abilities. Frontiers in Psychology 6, 519. https://doi.org/10.3389/ fpsyg.2015.00519

Klem, M., Melby-Levråg., M, Hagtvet., B, Lyster., S. A. H., Gustafsson, J. E., \& Hulme, C. (2015). Sentence repetition is a measure of children's language skills rather than working memory limitations. Developmental Science 18(1), 146-154. https://doi.org/10.1111/ desc. 12202

Logie, R. H. (2016). Retiring the central executive. Quarterly Journal of Experimental Psychology, 69(10), 2093-2109. https://doi.org/10.108 $\underline{0 / 17470218.2015 .1136657}$

Logie, R. H., \& Morris, R. G. (Eds.). (2014). Working memory and ageing. Psychology Press.

Melby-Lervåg, M., \& Hulme, C. (2013). Is working memory training effective? A metaanalytic review. Developmental Psychology 49: 270-291. https://doi.org/10.1037/ a0028228

Miller, G. A. (1956). The magical number seven, plus or minus two: Some limits on our capacity for processing information. Psychological Review, 63(2), 81-97. https:// doi.org/10.1037/h0043158

Morrison, A. B., \& Chein, J. M. (2011). Does working memory training work? The promise and challenges of enhancing cognition by training working memory. Psychonomic Bulletin \& Review, 18(1), 46-60. https://doi. org/10.3758/s 13423-010-0034-0

Nadler, R.T., \& Archibald, L. M. D. (2014). The assessment of verbal and visuospatial working memory with school age Canadian children. Canadian Journal of Speech-Language Pathology and Audiology 38, 262-275.

Paulesu, E., Shallice, T., Danelli, L., Sberna, M., Frackowiak, R. S., \& Frith, C. D. (2017). Anatomical modularity of verbal working memory? Functional anatomical evidence from a famous patient with short-term memory deficits. Frontiers in Human Neuroscience, 11, 231. https://doi.org/10.3389/ fnhum.2017.00231

Riascos, J. A., Brugger, A. M., Borges, P., da Luz Fontes, A. B. A., \& Barone, D. C. (2019, September). Reading Span Test for Brazilian Portuguese: An Eye-Tracking Implementation. In Latin American Workshop on Computational Neuroscience (pp. 104-118). Springer, Cham.

Vugs, B., Cuperus, J., Hendriks, M., \& Verhoeven, L. (2013). Visuospatial working memory in specific language impairment: $A$ meta-analysis. Research in Developmental Disabilities, 34(9), 2586-2697. https://doi. org/10.1016/i.ridd.2013.05.014 